\title{
Carrying Capacity OF Age-SPeCIFIC habitat Zones Within Black-TaIled Prairie Dog Colonies: A BaSeline Preceding Black-Footed FERRET REINTRODUCTION
}

\author{
GLENN E. PLUMB $\downarrow$ UW-NPS RESEARCH CENTER \\ UNIVERSITY OF WYOMING $\bullet$ LARAMIE
}

\section{$\checkmark \quad$ INTRODUCTION}

Plant-animal interactions vary strongly between habitat zones characterized by the duration of colonization (age-specific) within a black-tailed prairie dog (Cynomys ludovicianus) town (Cincotta et al. 1984). These interactions largely determine vegetation composition, diet composition and quality, and population demographics of habitat zones. The ecology of the black-tailed prairie dog in Badlands National Park (BNP) has been described by Cincotta et al. (1984) and Sharps and Uresk (1990). Yet, there is still uncertainty about the plant-animal relationships which underpin prairie dog carrying capacity in different habitat zones.

Understanding the variability in the ecology of black-tailed prairie dogs between habitat zones of mature towns is fundamental to successful reintroduction of the black-footed ferret (Mustela nigripes) into southwestern South Dakota. The predator-prey relationship between black-tailed prairie dogs and black-footed ferrets is dependent in large part upon density of prey. Additionally, an understanding of black-tailed prairie dog population and foraging ecology will be a required contribution by BNP to the development of a multiple large and small herbivore carrying capacity management model.

For the purposes of this proposal, carrying capacity is defined as an estimate of densities of prairie dogs supportable at different levels of forage availability and quality (Hobbs and Swift 1985). Of the habitat zones in an aging prairie dog town, the old-town centers (OTC) and young-town edge (YTE) zones offer the most widely differing habitat characterizations (Cincotta et al. 1984), and should provide the most interesting test of the effect of habitat quality on prairie dog carrying capacity. The objectives of this research are 1) To estimate the carrying capacity of black-tailed prairie dogs in different habitat zones of an aging town, and 2) To understand how vegetation characteristics and prairie dog feeding habits influence the number of blacktailed prairie dogs which can be supported in different habitat zones.

\section{BACKROUND INFORMATION}

Baseline information about vegetation, diets, and population demographics of black-tailed prairie dogs in BNP is provided in Cincotta et al. (1984).

VEGETATION COMPOSITION. YTE contain greater than $75 \%$ grass cover while OTC, which represent the strongest change in plant composition from uncolonized habitat, are characterized by greater than $75 \%$ forb cover. There is considerable interannual variation in aboveground standing crop within habitat zones but there is little difference in total growing season standing crop between YTE and OTC. 
DIET COMPOSITION AND QUALITY. Prairie dog diets generally consume greater than $85 \%$ grasses in their diets. However, prairie dog diets vary strongly between age-specific habitat zones. The ratio of forbs to grasses is approximately 0.2 and 6.3 in YTE and OTC respectively. Highly selective feeding is expressed by prairie dog inhabiting agespecific habitat zones within a prairie dog colony. Within OTC, Agropyron smithii is generally the only grass of importance to total standing crop but is selected for highly. Conversely, in YTE, where animals have opportunity to feed in various habitat zones including uncolonized mixed prairie, $A$. smithii is a relatively unimportant diet constituent. Forage digestibility also varies with colony age and vegetation composition. YTE forage is characterized by approximately $20 \%$ digestibility whereas OTC forage is characterized by approximately $35 \%$ digestibility. These differences are attributable to the inherent differences in digestibility between grasses and forbs. Since digestibility is well correlated with energy, dietary energy should be greater in OTC than in YTE.

POPULATION DEMOGRAPHICS. Juvenile recruitment in YTE is approximately two fold that of OTC. There is also a strong difference in immigration patterns between YTE and OTC. Numbers of female immigrants into YTE are much higher than expected from a random dispersal model whereas immigration into OTC is less than expected. Indeed, immigration of females into YTE is approximately eight times greater than that observed for OTC.

CARRYING CAPACITY. Given that prairie dogs maintain strong familial groups and appear to be limited to foraging with their coterie territory, how can similar densities of black-tailed prairie dogs be supported on strongly different habitat zones? Should differences in plant-animal interactions be reflected in variation in the carrying capacity of such habitat zones? Substantial differences in critical habitat nutritional variables suggest that this may be so. Carrying capacity of habitats for animals consuming diets at different levels of nutritional quality have been successfully predicted (Hobbs and Swift 1985). As such, habitats characterized by relatively lower forage quality but with higher biomass can support higher carrying capacities for animals consuming low quality diets. Conversely, habitats with lower amounts of high quality biomass may support more animals on a high plane of nutrition than expected solely on the basis of forage availability. It may be that differing age-specific habitat zones within a large colony provide compensating variables capable of supporting similar prairie dog densities. Planning for the successful reintroduction of black-footed ferrets into southwestern South-Dakota requires an understanding of the plant-animal relationships which may underpin prairie dog densities in age-specific habitat zones characterized by widely varying vegetation composition and quality and prairie dog feeding habits.

\section{$\checkmark \quad$ METHODS}

CARRYING CAPACITY. Carrying capacity is being determined using the algorithm described by Hobbs and Swift (1985). This model addresses the question: How much food is present in the environment that will allow a population of animals to obtain diets averaging a specific level of some nutrient (Hobbs and Swift 1985)? The sampling protocol largely mirrors that used by Cincotta et al. (1984) in order to be able to compare results of this study with earlier work in BNP.

All sampling occurred during late-July to early-August 1992, in six replicates paired in OTC and YTE habitat zones of BNP prairie dog town \#SC12 (Tyree site). Each replicate included two grid cells, each cell $25 \mathrm{~m} \times 25 \mathrm{~m}$. Biomass of forages was estimated by clipping three $0.10 \mathrm{~m}_{2}$ plots per cell at peak standing crop biomass in late July to early August. Samples were oven-dried at $40^{\circ} \mathrm{C}$ for 48 hours and weighed to the nearest $0.1 \mathrm{~g}$. Dry matter, nitrogen (protein $=\mathrm{N} \times 6.25$ ), and energy will be estimated for these forages. The amount of food available which permits specific diet quality levels and carrying capacity will be calculated according to Hobbs and Swift (1985). Carrying capacity is estimated by dividing food supply by dry matter intake (Hobbs and Swift 1985). Estimates of blacktailed prairie dog requirements (dry matter intake, nitrogen, and energy) will be taken from the literature.

Actual diet composition is being determined by estimating relative density of forages in prairie dog fecal samples. Composition of plant material in the feces will be estimated using the microhistological technique (Food Habits Laboratory, CSU). Density 
of prairie dogs in habitat zones was estimated by the visual count technique described for white-tailed prairie dogs by Menkens et al. (1990). Differences between observed and predicted diets and the effects of habitat zone are determined with paired t-tests. The relative importance of vegetation and population demographic variables (forage composition, forage biomass, forage quality, prairie dog recruitment and immigration [population data provided by Cincotta et al. (1984)]) to habitat zone densities will be also estimated.

\section{PRELIMINARY RESULTS AND INTERPRETATIONS}

Sampling substantiated that there are differences between OTC and YTE in forage composition (Table 1). Grass contributed 40 times more biomass to YTE than OTC $\left(\mathrm{t}_{(.05) 10}=9.147\right.$, $\mathrm{p}=0.00)$ while forb biomass did not vary $\left(\mathrm{t}_{(.05) 10}=\right.$ $0.450, p=0.66$ ). There was no difference $\left(t_{(.05) 10}=0.159, p=0.88\right)$ in visual counts of prairie dog density between OTC and YTE (Table 1). Visual count estimates (24 prairie dogs/hectare \pm 12 ) are lower than estimates derived by BNP (46 prairie dogs/hectare) from a 1989 line transect survey technique (Biggins et al. 1991) of the Tyree town (Bruce Bessken, BNP, personal comm.) There were fewer burrows per hectare in YTE that OTC $\left(t_{(.05) 10}=-2.763, p=0.02\right.$, Table 1). However, mean town-wide burrow density (no discrimination between habitat zones) $(163 \pm 44)$ does not appear different from the number of burrows per hectare (161) observed by BNP staff during the 1989 line transect survey of the Tyree town (Bruce Bessken, BNP, personal comm.).

Preliminary results generally raise more questions that they answer. These data suggest that during late July to Early August, similar densities of black-tailed prairie dogs occupy habitat zones which vary strongly in forage composition. OTC sites are probably a less stable foraging environment than YTE because of the lack of perennial grasses. Hence, how do these coteries sustain themselves during the nongrowing season in OTC when forb forages become unavailable? Perhaps, intra-town habitat use patterns vary seasonally with the availability of high quality forb forages in OTC. If so, temporal and spatial patterns of inter-town dispersal originating from larger, aging towns may differ from those patterns observed in young towns. Also, discrepancies in prairie dog densities between the grid-cell visual count (Menkens et al. 1990) and line transect (Biggins et al. 1991) procedures suggests that there may be biases incorporated into either technique when applied to black-tailed prairie dogs which may result in inaccurate estimates. Yet, similarity in mean town-wide (no discrimination between habitat zones) burrows density suggests that the line transect technique overestimates prairie dog densities in large, aging towns where patterns of habitat use may be variable and unaccounted for.

\section{WORK REMAINING}

1. Analyze diet composition data derived from microhistological analyses of fecal samples.

2. Analyze forage samples for nitrogen and energy.

3. Estimate fractional contribution of plant parts to total forage biomass.

4. Complete carrying capacity simulation modelling.

5. Estimate the relative importance of vegetation and population demographic variables (forage composition, forage biomass, forage quality, prairie dog recruitment and immigration) to habitat zone densities.

\section{$\checkmark \quad$ LITERATURE CITED}

Biggins, D., B. Miller, L. Hanabury, B. Oakleaf, A. Farmer, R. Crete, and A. Dood. 1991. A system for evaluating black-footed ferret habitat. Report prepared for the BlackFooted Ferret Interstate Coordinating Committee. U.S. Fish and Wildlife Service, 1300 Blue Spruce Dr., Fort Collins, CO. 53 pp.

Cincotta, R.P., D.W. Uresk, and R.M. Hansen. 1984. Ecology of the black-tailed prairie dog in the Badlands National Park. Final Report to the National Park Service, Rocky Mountain Regional Office, Denver, CO. Contract No. CX1200-1-B035. 55 pp. 
46

Hobbs, N.T. and D.M. Swift. 1985. Estimates of habitat carrying capacity incorporating explicit nutritional constraints. J. Wildl. Manage. 49:814-822.

Menkens, G.E., D.W. Biggins, and S.H. Anderson. 1990. Visual counts as an index of whitetailed prairie dog density. Wildl. Soc. Bull. 18:290-296.
Sharps, J.C. and D.W. Uresk. 1990. Ecological review of black-tailed prairie dogs and associated species in western South Dakota. Great Basin Nat. 50:339-345.

Table 1. Estimated forage composition (kg/ha) (August 1 - 5, 1993), black-tailed prairie dog density (\#/ha), and burrow density (\#/ha) of the Tyree prairie dog town, Badlands National Park, SD. Estimates derived for old town center (OTC), young-town edge (YTE) habitat zones, and town-wide (no discrimination between habitat zones).

\begin{tabular}{|c|c|c|c|}
\hline & $\mathrm{YTE}^{1}$ & $\mathrm{OTC}^{1}$ & Towr \\
\hline Grass & $400 \pm 90$ & $10 \pm 10_{b}$ & \\
\hline Forb & $970 \pm 280$ & $1040 \pm 230$ & \\
\hline \multicolumn{4}{|c|}{ Prairie Dog } \\
\hline Density & $24 \pm 12$ & $24 \pm 12$ & \\
\hline \multicolumn{4}{|l|}{ Burrow } \\
\hline \multirow[t]{2}{*}{ Density } & $133 \pm 28$ & $192 \pm 38_{b}$ & \\
\hline & Tov & & Town-wide $^{2}$ \\
\hline $\begin{array}{l}\text { Burrow } \\
\text { Density }\end{array}$ & & & 161 \\
\hline
\end{tabular}

1- Derived from visual count sampling per replicate grid cell (25 m x $25 \mathrm{~m}$ ) sampling design (Menkens et al. 1990) and destructive vegetation sampling.

2- Derived from line transect sampling design described by Biggins et al. (1991).

a- Mean pairs between treatments with different subscripts are significantly different $(p<.05)$. 